Both forms, although widely differing - the one in being an active, the other, a passive state-have, nevertheless, many similar symptoms.

\section{Of the Acute Form.}

The system, being reduced both physically and mentally, is but little able to stand against any mental emotion of a violent character. The intensity exerted by the exciting emotion of course varies in proportion to the previous deteriorating effect of the predisposing cause, and whilst, in one case, but a slight increase of mental exertion upsets the mind, in another, a more severe or more prolonged continuance of the exciting cause is necessars.

Although it will be found that various supposed causes may be alleged, still, I believe, that in the greater proportion of such cases the immediate exciting canse is the feeling of disgust at, combined with alarm for the consequences of, the patient's criminal conduct. Hence it is that feelings of their own unworthiness arise in such patients, and, under the impression that they have committed the unpardonable sin-have sinned against the Holy Ghost, and that a future world presents no hope of joy or happiness for them, as they are excluded from it by their past conduct, they frequently make attempts to terminate their own existence. Such an act is occasionally incited by hallucination of the aural organ; but I have not found that suicide is so frequently to be traced to this, as in other cases of mental aberration depending on other causes. As regards suicide, the greater frequency of this occurs in those whose cases assume a melancholic character with the excitement. Thus, of the thirteen cases of suicidal tendency, without any propensity to injure others, twelve of the cases occurred in the melancholic and maniacal forms, and only one in the demented. But even this solitary instance is remarkable; for although in the demented, impulsiveness is frequently exhibited, it is not observed that this temporary energy is employed by the patient in doing injury to himself. $\mathrm{He}$ rather expends it in doing injury to others, or to the objects around him, and the mind is too much destroyed to experience those emotions which are the chief cause of the suicidal efforts in these cases.

Another peculiarity of these cases is the tendency frequently exhibited to self-mutilation, and, as reports show, the attempts are not unfrequently successful. Thus is indicated an unsound reasoning power, the visiting on the supposed offending organs the faults of the ill-regulated mind.

As already stated, the delusions in many instances assume religions character, and hence it is that it is repeatedly found that the cause of the sufferer's condition is supposed to be religion. The delusions of this class generally are of the melancholic character stated above: fears that eternal happiness is lost; that they have no hope beyond the grave; that they have committed the unpardonable sin; or that they are unworthy to live. It is probable that many of those young men whose insanity has become developed through such revival meetings as have of late been held in various districts of Great Britain and Ireland, would, on searching inquiry, be found to be cases of the class now occupying our attention. But from the age and sex of those becoming insane subsequently to attendance at these meetings not being stated in the reports of other asylums which I have had opportunity to consult, I am unable to state the proportion and frequency of such cases.

From the true cause of the mental condition of these cases not being understood, the meaning of these reproaches for past conduct cannot be comprehended; and it is easily explained why a young man of apparently blameless life making these self-accusations is regarded by his friends as suffering from acute religious feelings, whereas remorse or fear has generally more to do with his condition than trne religious impression or conviction.

In some patients, actions of peculiar character are the result of the idea that, by so acting, a propitiation is made for the sin committed. The attempt to injure the genitals, to pass blood, and other similar acts, proceed from this; whilst in other instances the object of these actions may be to convince those around and themselves that they still have some power left. In these, the varions acts of violence or destructiveness are the result of their endeavours to test their powers and to convince those around.

In the other mental symptoms there is no great difference from those observed in acute maniacal cases depending upon other causes. There is the excited and restless manner the incoherence of language, the loss of sleep, and other indications of mania, but qualified by the characters peculiar to the form just described

Drring the acute furor liquid food will generally be taken without much difficulty. The tendency to constipation must be obviated. The pulse, although rapid, is weak and small. There is much irritability of the heart's action; but I have not observed that anæmic bruits accompany the heart's sounds in these acute cases

The tendency of the mental condition is generally towards recovery, but relapses may in a large number of oases be looked for; and so frequently do these occur that the case may assume a kind of recurrent form, but the continuance of this is limited by the approach of dementia.

During convalescence these patients generally betray their apathetic disposition. They do not care to employ themselves; there is a want of concentrative power; and they are easily tired by the ideas being fixed for but even a short time on any subject. It is also not unusual to find that delusion upon one subject or upon one class of ideas exists. Thus the patient may deny the possession of a portion of his body; and whilst one will deny the existence of his heart, another will tell you he has no tongue. It is also to be remarked that in these there is a great loss of self-reliance, and they are undetermined in their actions, frequently ask what they ought to do, and then become obstinately opposed to follow the advice given.

The physical characters of the acute form are not so well marked as in the fatuous cases. In the former, mental peculiarities chiefly determine the cases; in the latter, the physical indications, combined with the abeyance of mind, distinguish them.

The physical system is, as a rule, but indifferently developed. The muscles are small, soft, and flabby; the body is generally emaciated, the adipose tissue being but feebly stored up; the complexion is variable, but, though occasionally flushed, is, as a rule, pale; the gaze is not constantly averted, but in all the cornea will be found dull and the expression inanimate.

Such, then, are the indications of the first form. Excitement, with delusion of a melancholic cast, and frequently if not in most cases of a religious tendency, combined with a suicidal or a self-mutilating inclination, occurring in a thin or emaciated man, under the age of twenty-five, (who does not present evidence of organic cerebral disease, ) of generally pale complexion and averted gaze, but always with the dull cornea and expressionless countenance, would lead to the diagnosis of the cause. The termination may, if the predisposing cause is overcome, be in recovery; but if it be continued, or if recom. menced, the progress towards fatuity is certain.

(To be continued.)

ON

\section{THE SURGICAL TREATMEN'T OF SINUSES.}

By WATTER JESSOP, Esq., M.R.C.S. ENG., SURGEON TO THE GKNRRAL HOSPIPAL AND DISPENSARY, CHELTRNHAM.

ON many occasions I have experienced the greatest difficulty in effecting a permanent riddance of the disagreeables attendant upon long-existing sinuses of the groin. The following case was an exceedingly severe one:-

$J$. J- had suffered on three occasions from bubo in the right groin, and, declining the knife, had allowed suppuration on each occasion to progress in an irregular manner until the abscesses gave way of their own accord. For a period of seventeen months, while travelling in the colonies, he had suffered more or less from successive fistulous abscesses, until the whole groin became radiated in every direction with sinuses, some running to a considerable depth, and spreading above and beyond the situation of Poupart's ligament; others on to the forepart of the thigh, and down the bend between the scrotum and the thigh. On seeing him in December, 1858, eight distinct sinuses could be traced. For nearly six months he had been under treatment; injections, setons, rest, and pressure had entirely failed to heal a single sinus. The integument was much indurated and discoloured, and the patient's health greatly impaired. Directing a generous diet, I determined upon a renewal of rest and a careful adaptation of pressure; confining my patient to bed, the better to insure the application of well-regulated bandages. For nearly a month this treatment was scrupulously carried out, but with no good effect. Setons of silk were then tried, saturated in solutions of chloride of zinc, iodine, nitrate of silver, and such like stimulants. They simply increased suppuration. On removing
them, pressure was again resorted to, but equally without 
effect, although perseveringly applied for some little time. In one length of the principal sinus, through which it was impossible from its irregular nature to pass the full length of seton, it was necessary to cut down upon the probe and draw out the silk, leaving a further portion of the sinus untouched. To my surprise, this was the only part that had healed, a portion rather more than an inch in length. Arguing from this circumstance that if the continuity of each sinus were destroyed at certain intervals of its course, adhesive inflammation might be more readily induced, I proposed to my patient that he should submit to a trial of the experiment, and to this he willingly consented.

Passing a probe into each sinus a distance of an inch, or an inch and a half, I cut or nicked down on its point with a small lancet-shaped scalpel, so destroying the continuity of the canal at that spot. Withdrawing the probe, I repassed it from the point of incision for another inch, repeating the proceeding, and so on along the track of each sinus. In this way numerous small incisions were made. Pressure was carefully re-applied over the affected parts. Very little disturbance ensued, but the patient complained of more life and soreness in the groin than he had done at any other period of his case.

Pressure was retained for five or six days, and upon examination it was evident that adhesive inflammation had been set up, and that there was a fair probability of a permanent cure. In less than a fortnight the major portion of the sinuses had quite healed. Those which had failed were again treated in a similar manner, and the second operation proved entirely successful.

I saw this patient at intervals for nearly six months after convalescence, and on seversil occasions carefully examined him. There was no symptom of a sinus remaining, and the thickened and discolourer? integument was much improved in appearance and character; the patient's health, also, in every way was re-established.

T. M-, a mate in one of the Australian line of clipper ships, consulted me in February, 1860. Two long irregular sinuses had existed in the left groin for upwards of seven months; and a pustular eruption spread over the scrotum and thigh, evidently occasioned by the irritative nature of the secretion from the sinuses. His case was treated in a simila manner to the preceding one. The single operation was sufficient, and, under pressure, the whole had healed in twelve days. This patient I have not seen since.

The proceeding referred to in these cases is simple, effectual, and really productive of very little suffering. The sinuses were of so extensive a character, and involved so wide a surface of unhealthy integument, as to preclude all appeal to the vigorous use of the bistoury, or the application of the heated platinum wire-an admirable plan introduced by Mr. Marshall, of University College Hospital, and published in the "Medico. Chirurgical Transactions" for 1851. Pressure and rest, and careful attention to the general health, had been tried, over and over again, without avail; and not the slightest progress was made until the continuity of each fistulous track was destroyed at intervals, and in the manner above-mentioned.

The cure was more certain and speedy than I had hoped for, and possibly a more extensive trial of the operation by other surgeons may confirm my experience so far in the treatment of these annoying and obstinate cases,

Royal-crescent, Cheltenham, 1861.

Royal Mrdical Benevolent College. - A special general meeting of the governors of this institution was held at the office in Soho-square on Monday last, the Earl of Powis in the chair, for the purpose of electing a president in the place of the late Earl Manvers, and for some other business. Mr. Propert proposed and $\mathrm{Mr}$. Webb seconded a resolution, " That the Right Hon. Lord Chelmsford be appointed President of the Royal Medical Benerolent College," which was unanimously agreed to. A resolution was then passed authorizing the trea. surer to receive all moneys coming to the College by gift or bequest, and to give valid receipts for the same; and another resolution authorizing the council to give permission to the widows of pensioners who may die at the College to remain there, and retain the benefits enjoyed by their late husbands. A vote of thanks to the chairman was then proposed by Dr. Conolly and seconded by Sir Charles Locock. In acknowledging it, the Earl Powis expressed a hope that all the governors then present would meet him again at Willis's Rooms on the 17th of May, when he had promised to take the chair at the annual festival of the College. The meeting then broke up.

\section{If flitror}

OF THE PRACTICE OF

\section{MEDICINE AND SURGERY IN THE}

HOSPITALS OF LONDON.

Nulla est alia pro corto noscendi via, nisi quam plurimas et morbornm ek dissectionum historias, tam aliorum proprias, collectas habere et inter se comparare.-Mongagmi. De Sed, et Cazus. MTorb., lib. 14. Proønium.

\section{IONDON HOSPITAL.}

IXGUINAL HERNIA, WITH UNDESCENDED TESTES; PaRtial REDUCTION; OpERATION; RECOVERY.

(Under the care of Mr. CuRling and Mr. Hutchinson.)

A MAN, aged thirty-two, a farm labourer, was sent to this hospital by a surgeon in a neighbouring village, on Thursday, the 14th ult. He broght with him a written statement that he was suffering from "strangulated hernia;" but no other information was given. On examination, he was found to be the subject of non-dexcended testes on both sides, the scrotum being wholly undeveloped, and the testis on each side a small, flabby organ, being retained just external to the outer inguinal ring. He stated that he had never worn a truss, and had never been the subject of rupture. He was married, and the abnormal position of his testes had never given him any trouble. On the previous Tuesday (i. e., forty-eight hours before), in jumping out of a cart, he had felt something slip down in the left side, and had soon after experienced severe pain there. During the following day he continued in pain, and with a ten. dency to sickness. On the Thursday morning he sent for. a surgeon. The tumour in the left groin was now the size of an egg, according to his statement; but after the attempt at the taxis which was made, it wholly disappeared. The bowels had not acted since the date of the protrusion.

As the man lay in bed there was a decided fulness visible in the left groin as compared with the right; but it was only slight, and to the hand no swelling was perceptible. The testis and the parts about were tender; but not extremely so. The abdomen was not at all swollen, and the man bore the firmest pressure without flinching. No actual sickness was now present; but the patient's countenance was decidedly anxious.

Mr. Curling, Mr. Hutchinson, and Mr. Maunder met in consultation; and, after careful investigation of the case, it was decided to wait. There was no proof that the hernia had not been wholly reduced; and it was quite possible that what of tenderness remained might be due to the contusion of the misplaced testis in the attempts at taxis. It was agreed not to give an opiate for fear of masking the symptoms, and to see the man again in four hours. A fomentation was ordered to the abdomen.

At eight in the evening Mr. Hutchinson again saw the patient. He had vomited once, and had retched a good deal; but with this exception had not been much disturbed since the afternoon. The fulness in the left groin was still present, and was somewhat increased when the man was made to stand up and to cough. A decided impulse on coughing could be felt in the upper part of the inguinal canal. The finger could be passed into the external ring, and no protrusion could be felt there. Considering the continued presence of sickness in a case in which there was a history of a reduction of a hernia as a symptom which did not admit of delay, Mr. Hutchinson determined at once to perform an exploratory operation, and in this decision Mr. Maunder, who was present, expressed his concurrence.

The man readily consented to the operation, and was at once taken to the theatre. Chloroform having been given, $\mathrm{Mr}$. Hutchinson laid bare the inguinal canal by an oblique incision upwards and outwards. The testis was found just external to the outer ring; the finger having been introduced into the latter, the tendon of the external oblique was slit up for about 